\title{
Research on the Application of Chinese Traditional Culture on Public Art Design
}

\author{
Yue Fan \\ Xi'an Siyuan University, Shaanxi, Xi'an, 701138
}

Keywords: Chinese Traditional Culture, Public Art Design, Application Study

\begin{abstract}
Public art design, as a "young" category of art, how to maintain its national personality at the same time, facing the world, facing the times, it is worth the majority of art designers and art researchers in-depth thinking. This paper makes a comprehensive and systematic study on the application of Chinese traditional culture in public art design, and tries to sort out the internal relations between Chinese traditional culture and public art design from the table and the present, and put forward the traditional culture As the source of creation, the development of China's public design of some of the innovative theory and ideas, hoping to other efforts to public art design research scholars to provide some valuable information.
\end{abstract}

\section{Introduction}

The topic of public art design and traditional Chinese culture is one of the hot issues discussed in the field of art design. Although China's public art design is based on the use of foreign culture based on the establishment, but this does not mean that we do not have the ability to develop their own characteristics of art design. Chinese traditional culture is very rich in nutrition, but the lack of Chinese art and design in the field of the phenomenon of personality still exists, has not yet achieved the true sense of the mainstream "Chinese design", art design is still facing some embarrassment. So far, many of the practical issues for this discussion is only one-sided and fragmented, so it is necessary to conduct a comprehensive and systematic study. Yesterday is the history of today, today is tomorrow, we live in reality and history, the traditional culture is "history", product design is "this", the study of the focus of the topic is "ancient for today, by ancient open today" Is based on the traditional national culture, the historical heritage as a fresh object, to the rough and fine, to the pseudo-true, inherited the spiritual achievements of the predecessors, based on the essence of China's outstanding traditional culture, and create a resort to modern product design To go. This is also a traditional culture of the heritage and development, formed in the context of Chinese culture, in line with the Chinese aesthetic concept, regional art and design. Under the strong cultural impact of the West, we should explore the infiltration of the culture in the public design, explore the concrete application of its culture in the design, and think about how to form the artistic design with our national characteristics. In the future of art design, we design all aspects will be related to traditional culture, and traditional culture is the source, we design the soul of the main thinking. We strive to change the way of thinking in the past, so as to constantly update the design style and form to meet the needs of the development of modern society. Inherit and carry forward the traditional design culture, so that the Chinese design with national style and modern characteristics, is every art designer and researcher should shoulder the responsibility. The above is the origin and significance of this topic.

\section{Public Art Design Development and Problems}

After the reform and opening up, the concept of art design really entered China. With some traditional industries and handicrafts as a result of slow development and gradually decline, coupled with some countries in Europe and the United States the invasion of advanced culture, China's art and design once deviated from the healthy development of the track, there is no Chinese only 
English packaging design everywhere, the city Began to rise the design of foreign small Western-style, fashion is just blindly copied the design of Europe and the United States, many designers in the stagnant state of confusion. However, this situation was soon to Jin Diqiang and Han Meilin, represented by the outstanding designers of the break. Jin Diqiang in the design by adding a lot of Chinese elements, the five thousand years of Chinese culture through the form of art design presented, the art and science, traditional culture and modern public design perfect together. He stressed that this blend is not simply summed up, but in the deep understanding of Chinese culture on the integration. For example, the logo of the Bank of China in the design and suspension of the building on the floor, that is, the design of cultural ideas embodied. Han Meilin's art and design, but also inherited the Chinese culture and traditional art at the same time, absorb the essence of Western art. He advocates the art emphasizes the personality, emphasizes the national and the regional, the artistic success lies in the "root", as the Chinese artist, wants to "combine in the ocean to the main" "ancient and modern combination to present" .2008 Beijing The success of the Olympic logo logo design is the embodiment of this design idea. At the beginning of the century, China emerged a large number of excellent designers, they are active in the design field of various professional, leading the contemporary "Chinese design" development, its works in the design level and its cultural connotation than in the past have a larger The breakthrough and leap. It is worth mentioning that a series of successful Beijing Olympic design, so that the world and people see the Chinese art and design has entered a higher stage.

In today's Chinese design community seems to be a group of prosperity at the same time, we can not avoid and must be soberly facing our overall design level is still not balanced and some of the problems exposed. First, some designers lack the understanding and understanding of traditional culture The With the popularity of Internet and computer technology, the impact of globalization on China's modern design is deepening, making the Chinese design "international" features more obvious. Designers began to consciously understand, learn and imitate the Western art design, over-pursue "used doctrine", one-sided understanding of "all things return", do not consider the cultural background of the object and aesthetic habits. They use the abstract, geometric visual symbols instead of the traditional Chinese graphics and aesthetic taste, some elements of simple patchwork, such irresponsible design in today's market is not uncommon. Second, some designers are vulnerable to the impact of popular factors. They blindly learn from the classic design, some of the popular form of imitation, resulting in a visual similarity, ignoring the work itself should be revealed the content and mood, so that the work of its loss of recognition, in the design of creativity, for Spatial understanding and overall grasp of space, cultural connotation, aesthetics, traditional inheritance, development and other comprehensive aspects of cultivation, showing a strong materialism and utilitarian tendencies.

\section{Main Elements of Chinese Traditional Culture}

Everything from the traditional culture to draw a representative of things, we can call it "traditional cultural elements." Chinese civilization up and down five thousand years, followed by the formation of a wide range of topics, rich in content, diverse forms, spread long tradition of cultural elements, they are oriental culture in the unique landscape and valuable wealth, other forms of art is difficult to replace in the world Art of the forest in its unique charm of the Oriental culture shine. Chinese traditional culture elements include Chinese calligraphy, seal, Chinese knot, Qin brick Hanwa, Beijing opera mask, shadow, Chinese lacquerware, Han Dynasty bamboo slips, Oracle, Wenfangsibao Yantai, brush, Xuan paper, ink vertical cable binding, paper cutting, kite, wishful Chinese painting, Chinese painting, Dunhuang murals, lions, Tang suit, chopsticks, Chinese characters, gold ingot, wishful, gossip, etc., will be used in the arts, You can use the United States and the United States, with the design, you can exquisite, this is the great elements of these traditional cultural and magical effect. Here we are on the traditional Chinese culture in several major elements of the performance of a brief introduction.

Writing as a written symbol of language is an effective means of passing information and exchanging emotions. Chinese characters are the crystallization of the wisdom of the Chinese nation, 
after a long period of evolution, evolution, before the formation of today's mature form. At present, the world's common text has "meaning text" and "letter text" two categories. Chinese characters are representative of the text of the word, is based on the hieroglyphics on the basis of a long evolution of the square word, through the pictograms, knowing and other six means to convey a specific intention. At the beginning of the word with the graphics features, with self-description of the ability to leave people's memory and interpretation of independent transmission of a certain information. So far, after thousands of years of Chinese characters, still filled with strong vitality and unique artistic charm. At the same time, Oracle, Zhuan, Li, Kai and other books of different representations for the design provides a rich visual elements. With the development of the times, standing on a broader information platform to examine, never divorced from the world of things "like" and "shape", and the image of a high degree of simplicity and generalization of Chinese characters, is undoubtedly a very vitality and Appealing design elements.

\section{The Application of Chinese Traditional Culture on Public Art Design}

On the "advertising", the earliest records in Chinese history can be traced back to the Warring States period, "Han Feizi" described in the "very high" in the "look" is one of the embryonic form of advertising to the Song Dynasty, printing "leaflets" The production is also an early form of advertising. Visible, advertising in China is a long history. However, advertising really becomes a professional activity and plays its great role is derived from the capitalist society. Therefore, it can be said that China's advertising art is introduced by foreign countries. Here, we select the common form of posters advertising to glimpse the traditional Chinese culture in the application of advertising design. Poster advertising is a very popular advertising genre, used to complete a certain campaign to encourage the task, or for the report, advertising, advice, education and other purposes of service. In China, posters advertisements are divided into two kinds of posters for public welfare or cultural propaganda, called public welfare or cultural posters or short posters for commodities, which are called commodity advertising posters or commodity posters. The signature of the Chinese posters is the month of the twenties and thirties in the emergence of coastal cities in the month of advertising and road signs advertising. They think that the masses loved the form of deep into the tens of thousands of households, is the development of posters advertising and the beginning.

Post post advertising is characterized by a clear, concise and clear, people in a moment and a certain distance can clearly see the things to be promoted. To this end, the design often take certain assumptions, highlight the focus, save the secondary details or background, you can different proportions, and different time, space activities combined, you can also use symbolic means to inspire people's association. Therefore, the poster design should be able to overload the reality, the composition should be concise, the image should be simple and exaggerated, with a strong and distinctive colors for the way, highlight the expression of the things to be publicity to express the relationship between things and things, given The broader meaning of the screen and make people in a limited picture can be associated with a broader life, feel the new meaning. In these areas, the profound Chinese traditional culture for the designers to provide a lot of nutrients and valuable source of creation, works always reveal the traditional culture of the aesthetic sense of subtle influence. Below, we make a brief analysis from this point of view.

\section{Conclusion}

With the enhancement of the consciousness of traditional Chinese culture, our "traditional culture" design theory will mature. China's art and design theory will become the necessary prerequisite and conditions for the multiple dialogue of the First World and the traditional Chinese cultural language complement each other, symbiosis and common prosperity. The social responsibility of any art designer is, above all, his responsibility for his own tradition, and if a designer can not express himself creatively and develop the traditional culture itself, he also loses his prerequisites and conditions as a design art. It is inevitable to agree with and succumb to a repressive discourse practice of the first world. Our predecessors created yesterday's traditional 
culture, we are creating tomorrow's traditional culture, the traditional culture has made the history of human civilization, Chinese traditional culture, will continue to play its huge, ubiquitous influence, so that the Chinese art Design has a profound background and unique style.

\section{References}

[1] Zhen Zhen. Environmental Ceramics of the spatial integrity [J]. Fine Arts. 2008 (08)

[2] Wu Hongliang. Olympic sculpture - the national public relations important cultural weight [J]. Sculpture. 2008 (04)

[3] Huang Huanyi, Zhu Jinhua. Environmental Ceramics Design and Urban Cultural Features [J]. Chinese Ceramics Artists. 2007 (02)

[4] Jiang Shengjie, Jiang Xiaolan. The public nature of environmental ceramics [J]. China Ceramics. 2007 (05)

[5] Wu Xing'an, Xu Xiaohong. Aesthetic characteristics and spatial representation of environmental pottery [J]. Chinese Ceramics. 2006 (11)

[6] Cheng Fei. Environmental pottery on the participation of public art [J]. China Ceramics. 2006 (07) 